\title{
BMJ Open Evidence-based development of a post-surgical lumbar discectomy leaflet intervention: a Delphi consensus study
}

\author{
P C Goodwin, ${ }^{1}$ C C Wright, ${ }^{2}$ C Allan, ${ }^{3}$ L Crowther, ${ }^{4}$ C Darley, ${ }^{5}$ A Heap, ${ }^{6}$ E Paul, ${ }^{7}$ \\ L White, ${ }^{6}$ A Rushton ${ }^{2}$
}

To cite: Goodwin PC, Wright CC, Allan C, et al. Evidence-based development of a post-surgical lumbar discectomy leaflet intervention: a Delphi consensus study. BMJ Open 2015;5:e006069.

doi:10.1136/bmjopen-2014006069

- Prepublication history for this paper is available online. To view these files please visit the journal online (http://dx.doi.org/10.1136/ bmjopen-2014-006069).

Received 8 July 2014 Revised 14 February 2015 Accepted 16 February 2015

CrossMark

For numbered affiliations see end of article.

Correspondence to Dr P C Goodwin; p.goodwin@mmu.ac.uk

\section{ABSTRACT}

Objective: To produce free, expert-informed postoperative information for lumbar discectomy patients, satisfying UK National Health Service Information Standards.

Design: A mixed methods approach utilising the Delphi technique and focus groups.

Setting: Five spinal centres across the UK.

Participants: Panel members included 23 physiotherapists, 11 patients and 17 spinal surgeons. Intervention: Three rounds of questionnaires including open and closed questions and attendance at a clinician/patient focus group.

Results: Response rates of $85 \%, 26 \%$ and $35 \%$ were achieved for the Delphi rounds. Ten clinicians and six patients participated in the focus groups. Consensus for leaflet sections was achieved in round 1 and content in round 3. The focus groups informed further revisions.

Conclusions: A consensually agreed, Information Standard compliant, patient lumbar discectomy leaflet was produced containing: (1) normal spine anatomy;

(2) anatomy disc herniation and surgery; (3) back protection strategies and (4) frequently asked questions. Illustrations of exercises enable tailoring to the individual patient.

\section{INTRODUCTION}

Lumbar discectomy surgery is conducted to excise part of a prolapsed intervertebral disc. First-time lumbar discectomy operations in the UK National Health Service (NHS) increased from 7043 (2001-2002) to 9397 (2009-2010) and 8584 (2010-2011). ${ }^{1}$ The mean hospital stay for first-time lumbar discectomy has reduced from 6.6 days (1999-2000) to 2.6 days (2011-2012). ${ }^{1}$ This reduction affords patients less time to discuss postoperative anxieties ${ }^{2}$ and rehabilitation, thereby increasing the importance of written patient education as an integral component of postoperative rehabilitation. However, current provision of written information varies widely in content, quality and provider. $^{3-5}$

In $2006,35 \%$ of surgeons provided patients with written instructions ${ }^{4}$ and, in $2007,73 \%$

\section{Strengths and limitations of this study}

- This study addresses the lack of a freely available, evidence-based leaflet, solely for lumbar discectomy patients, which satisfies the requirements of the UK National Health Service Information Standard.

- We produced, through consensus of experts including surgeons, patients and physiotherapists, a patient leaflet that can be adopted by hospitals. The content of the leaflet included items lacking in existing information such as tailored exercises, when to start activities and the relationship between exercises and driving.

- We experienced a low and unbalanced return rate in the Delphi, which could lead to the possibility of bias towards physiotherapists' views, however, the patient focus groups will have gone some way in rebalancing this.

- The effectiveness of this patient leaflet is unknown and has yet to be included as an intervention as part of a randomised controlled trial.

of patients were provided with written and/ or verbal advice by a physiotherapist post first-time lumbar discectomy. ${ }^{5}$ However, variability of information was problematic, for example restrictions on sitting, driving and returning to work varied considerably. ${ }^{3-5}$ Information such as fatigue after surgery was largely ignored. ${ }^{6}$

Traditionally, in the UK, patient information is developed locally by physiotherapists and/or surgeons without any scientific method or evidence base. Other information such as "Get well soon"7 and 'Your Back Operation $^{8}$ is available via the internet, but is not issued by the NHS, not widely adopted, or incur a cost. McGregor et a ${ }^{\ominus}$ included 'Your Back Operation' leaflet in a randomised controlled trial (RCT) following discectomy or decompression surgery $(n=338)$ finding no effect of the leaflet or rehabilitation and leaflet combined on patient function postsurgery. Despite this, 
they found that providing the leaflet to discectomy patients achieved modest gains at a low cost, but acknowledged this requires further investigation. To the best of our knowledge, no freely available leaflet has been developed specifically for discectomy/microdiscectomy patients in Europe.

Following a literature review ${ }^{10}$ it was concluded that the type of exercise and effectiveness of physiotherapy interventions most beneficial to this population remains unclear. Selkowitz et $a l^{11}$ created a leaflet for use in a trial post lumbar microdiscectomy in the USA. Unfortunately, it was not directly transferable to patients in the UK as it had an introduction related to an RCT and questions for the patient to answer. It did not contain patient exercises and it lacked an explanation of the evidence behind its development. However, it comprised four salient sections: normal anatomy of the spine; anatomy of disc herniation and the surgery following it; strategies on how to protect your back; and frequently asked questions.

An audit of 16 spinal surgery centres in England and Wales (2012) determined the written information provided by physiotherapists post lumbar discectomy. All centres used in-house leaflets. They were agreed on by the physiotherapists and surgeons, but based on clinical experience because of the lack of an evidence base. Most centres planned to review their leaflet and only two centres were aware of the 'Your Back Operation' leaflet, but neither used it owing to cost and it not including exercises. None were aware of any other patient information produced for lumbar discectomy patients including the 'Get well Soon' or Selkowitz et $a l^{11}$ leaflets.

The aim of this study was to produce a freely available, evidence-based lumbar discectomy leaflet, designed by experts, that satisfies requirements of the UK National Health Service Information Standard. ${ }^{12}$

\section{METHODS}

Design

A mixed methods study included the Delphi method, followed by focus groups, to obtain stakeholder consensus of leaflet structure and content. The Delphi method has previously been used in low back problems ${ }^{13}{ }^{14}$ and for developing patient information. ${ }^{2}$ Key benefits include its potential to invite experts as panel members without face-to-face meetings, and its facilitation of participants' reconsideration of opinions. Focus groups then enabled discussion of content, wording and layout of the developed patient leaflet.

\section{Delphi method}

\section{Panel members}

Delphi panel members were selected through purposive sampling to ensure that membership had in-depth knowledge of the problem from different perspectives: spinal surgeons (orthopaedic and neurological), inpatient and outpatient physiotherapists involved in the care of discectomy patients, and recent postoperative disctectomy patients. The intention was to obtain a panel of approximately 60 members containing three equal groups of 20.

\section{Round 1}

Round 1 questions were formulated and piloted by clinical staff and an academic member of physiotherapy staff who had recently experienced lumbar discectomy surgery. Feedback focused on readabilty, relevance and appropriateness of the questions. A letter, patient information sheet and questionnaire were sent to the lead physiotherapist at five centres for spinal surgery in England, who identified clinician and patient panel members. Consent was obtained through return of completed questionnaires (post/email). Reminds were sent twice by email/telephone.

Round 1 asked whether the content of a leaflet should be based around the four headings identified by Selkowitz et al. ${ }^{11}$ The inclusion of each heading required a response on a 5 point Likert scale ( $1=$ strongly disagree, $2=$ disagree, $3=$ neutral, $4=$ agree, $5=$ =strongly agree). Open questions requested suggested content under each heading.

In each round, item consensus was established by: mean rating $\geq 3.5$ on the 5 point Likert scale; coefficient of variation (CV) $\leq 30 \%$; and $\geq 80 \%$ of responses scoring 4 or 5 (ie, round $1=$ agree or strongly agree; round 2 and $3=$ important or very important). A mean rating $\geq 3,{ }^{15}$ and minimum percentage of agreement of $75 \%$ have previously been accepted as consensus. ${ }^{16}$ The mean rating of $>3.5$ and percentage agreement of $80 \%$ were increased owing to an anticipated wider variation of priorities from the different stakeholders.

Items not reaching consensus were removed from future rounds. Overall agreement between panel members was calculated both for the whole questionnnaire in round 1 and each section in rounds 2 and 3 using Kendall's Coefficient of Concordance, ${ }^{17}$ employing a significance level of 0.05. Data from open questions requesting suggested content under each heading were collated and analysed for emerging themes/subthemes by two authors (PCG, AR) independently. Agreed themes/subthemes comprised the topics for round 2 .

\section{Round 2}

Themes/subthemes from round 1 were proposed to the panel as potential leaflet content using a combination of open and closed questions. For example, a closed question was "How important is it to you that the following structure should be used in this section?" Panel members responded to closed questions using a 1-5 Likert scale with the anchors, $1=$ not important, $5=$ =very important. For each section, open questions seeking further comments were included. 


\section{Round 3}

Items reaching consensus were included in round 3. Any answers from open questions in round 2 were also included for consideration. The panel completed the same Likert scale as round 2 to determine item importance. An open question seeking any further comments was included for each section. Consensus for each item was determined as round 2. Items that did not reach consensus were removed. Data from open questions were grouped according to whether they referred to leaflet content or structure and analysed as previously. Items demonstrating consensus informed the draft leaflet.

\section{Focus groups}

Two focus groups $(n=10$ physiotherapists, $n=6$ patients) were $^{\text {conducted }^{18}}$ to explore the draft content and design of the leaflet. All panel members provided written consent to participate and for discussions to be recorded. An introduction in each focus group described the leaflet and agreed ground rules for the discussion. Setting ground rules encourages open debate and prevents animosity and aggression influencing group discussions. ${ }^{13}$ The group facilitator (AR) sought feedback on the draft leaflet using semistructured questions regarding content and design, and observers (LC and CCW) recorded key issues in writing. Following analysis of key themes (AR/ $\mathrm{CCW}$, recommendations were summarised and incorporated into the leaflet.

\section{RESULTS}

\section{Delphi method}

Round 1

In round 1,51 of 60 questionnaires $(85 \%)$ were returned. Panel members included 23 physiotherapists, 11 patients and 17 spinal surgeons. Agreement between panel members for the four headings proposed in round 1 was strong $(\mathrm{W}=0.609, \mathrm{df}=36, \mathrm{p}<0.05)$. Table 1 shows the mean rating, $\mathrm{SD}, \mathrm{CV}$ and percentage of those who 'agree' or 'strongly agree' with the inclusion of each heading. Themes and subthemes derived from the open questions were organised within each heading (table 2).

Table 1 Responses from round 1, rating whether the content of a leaflet should be based around the four headings identified by Selkowitz et $a l^{11}$ (1=strongly disagree, $5=$ strongly agree)

\begin{tabular}{|c|c|c|c|c|}
\hline Heading & Mean & SD & $\begin{array}{l}\text { CV } \\
(\%)\end{array}$ & $\begin{array}{l}\text { Agreement } \\
(\%)\end{array}$ \\
\hline $\begin{array}{l}\text { 1. Normal anatomy } \\
\text { of the spine }\end{array}$ & 4.3 & 1.1 & 26 & 81 \\
\hline $\begin{array}{l}\text { 2. Anatomy of disc } \\
\text { herniation and the } \\
\text { surgery following it }\end{array}$ & 4.4 & 1.1 & 25 & 89 \\
\hline $\begin{array}{l}\text { 3. Strategies on how } \\
\text { to protect your back }\end{array}$ & 3.9 & 1.6 & 41 & 86 \\
\hline $\begin{array}{l}\text { 4. Frequently asked } \\
\text { questions }\end{array}$ & 4.4 & 1.0 & 23 & 76 \\
\hline
\end{tabular}

\section{Round 2}

In round 2, 234 questions were included. Sixteen panel members responded (26\%) including 13 physiotherapists, 2 patients, and 1 surgeon. Non-response was followed up and was due to workload, long-term absence or departure from Trust. Overall panel agreement (table 3) was not reached for items under the heading 'Normal anatomy of the spine' (W=0.235, $\mathrm{df}=14$, $\mathrm{p}>0.05$ ), and only $25 \%$ of items under this heading were taken forward to round 3 . The strongest agreement between panel members was for items under the 'Frequently asked questions' heading. Most items taken forward to round 3 were under the heading 'Strategies on how to protect your back'. Some items under the heading 'Other headings or comments' were repeated in other sections. They remained in the questionnaire for round 3 so that panel members had the option to identify repetition.

\section{Round 3}

The questionnaire in round 3 contained 103 items. Twenty-one panel members $(35 \%)$ responded, including 16 physiotherapists, 3 patients and 2 surgeons. More panel members felt they could respond in round 3 owing to the lower number of questions. After the three rounds, agreement between panel members was stronger (table 4) with agreement across all items in the questionnaire reaching significance $(\mathrm{W}=0.213, \mathrm{df}=20$, $\mathrm{p}<0.05)$. In particular, $100 \%$ of items under the heading 'Normal anatomy of the spine' reached consensus. All items reaching consensus were included in the draft leaflet.

\section{Focus groups}

Discussion regarding the draft leaflet was positive. Patients preferred an A5-sized leaflet in portrait orientation, with anatomical detail, fewer technical terms and more lay terms about anatomy of the spine and disc and technique and purpose of exercises. Patients suggested to "omit technical language from all diagrams e.g. plantarflexion and dorsiflexion, but the word 'stability' can stay." Patients requested examples of how to maintain fitness, examples of what 'normal activities' might include, and examples of 'high and low impact exercises'. Patients understood and wanted timescales, but wanted to include a sentence to reassure patients that "everyone is different and will recover at a different rate...you might be able to do more or less than it suggests against each timescale."

The discussion with the physiotherapists focused on terminology throughout the leaflet and alongside the illustrations. The physiotherapists recommended changes to instructions, "for all exercises, remove the anatomical movement in brackets and any other technical jargon." They requested timescales be extended from ' 8 weeks onwards' to ' 12 weeks onwards.' They wanted to 'clarify that the aim of the surgery is to address leg symptoms and requested more reference to 
Table 2 Themes identified from round 1 open questions

\begin{tabular}{|c|c|}
\hline Themes & Subthemes \\
\hline \multirow[t]{6}{*}{ Normal anatomy of the spine } & Key principles of the section \\
\hline & Explanations of anatomy \\
\hline & Explanations of function \\
\hline & Explanation of disc protrusion \\
\hline & Illustrations \\
\hline & Terminology to be used in this section \\
\hline \multirow[t]{9}{*}{ Anatomy of disc herniation and the surgery following it } & Structure of the section \\
\hline & Key principles of the section \\
\hline & Language to be used in this section \\
\hline & Diagrams \\
\hline & Descriptions of a disc herniation \\
\hline & Benefits and potential risks of surgery \\
\hline & Advice about going home \\
\hline & Explanations of the surgical procedure \\
\hline & Effects of the herniation on the nerves \\
\hline \multirow[t]{6}{*}{ Strategies on how to protect your back } & Key principles of the section \\
\hline & Messages on prevention \\
\hline & Terminology \\
\hline & Immediate postoperative advice \\
\hline & Advice about specific aspects of function \\
\hline & Advice about exercises \\
\hline \multirow[t]{3}{*}{ Frequently asked questions } & Key principles of the section \\
\hline & Format of the section \\
\hline & Questions that should be asked \\
\hline \multirow[t]{10}{*}{ Other headings or content } & Postural advice \\
\hline & Information from previous patients \\
\hline & Items on short-term self-care \\
\hline & Injury recurrence \\
\hline & Dos and don'ts \\
\hline & Surgery information \\
\hline & Exercise advice \\
\hline & Restoration of function \\
\hline & Future care \\
\hline & Precautions \\
\hline
\end{tabular}

leg symptoms throughout the leaflet. They also requested a conclusion that "the surgery might or might not relieve the patient's back pain."

\section{The final leaflet}

The final leaflet (table 5) included a purpose, spine anatomy, the problem, the solution and advice during the hospital stay, going home, short-term and long-term goals, exercises with art work and the ability for individual tailoring (repetitions and frequency), pacing advice and frequently asked questions. References can be updated as new literature becomes available. Useful contacts included phone numbers and website addresses of the charity BackCare and NHS Choices, which has information about the symptoms, causes, diagnosis, treatment and prevention of a slipped disc.

\section{DISCUSSION}

The aim of this study was achieved and an evidencebased leaflet solely for lumbar discectomy patients was

Table 3 Summary of agreement across the panel members in round 2

\begin{tabular}{|c|c|c|c|c|c|}
\hline Heading & $\begin{array}{l}\text { Consensus } \\
\mathrm{N}(\%)\end{array}$ & CV & Kendall's W & df & p Value \\
\hline 1. Normal anatomy of the spine & $7(25)$ & 17 & 0.235 & 14 & 0.060 \\
\hline 2. Anatomy of disc herniation and the surgery following it & $22(45)$ & 19 & 0.133 & 15 & $<0.001$ \\
\hline 3. Strategies on how to protect your back & $28(56)$ & 16 & 0.198 & 15 & $<0.001$ \\
\hline 4. Frequently asked questions & $23(40)$ & 18 & 0.408 & 15 & $<0.001$ \\
\hline 5. Other headings or comments? & $14(38)$ & 17 & 0.244 & 15 & $<0.001$ \\
\hline
\end{tabular}


Table 4 Summary of agreement in round 3

\begin{tabular}{|c|c|c|c|c|c|}
\hline Heading & $\begin{array}{l}\text { Consensus } \\
\mathrm{N}(\%)\end{array}$ & CV & Kendall's W & df & p Value \\
\hline 1. Normal anatomy of the spine & $7(100)$ & 19 & 0.428 & 20 & $<0.001$ \\
\hline 2. Anatomy of disc herniation and the surgery following it & $14(67)$ & 18 & 0.264 & 20 & $<0.001$ \\
\hline 3. Strategies on how to protect your back & $20(71)$ & 20 & 0.416 & 20 & $<0.001$ \\
\hline 4. Frequently asked questions & $20(87)$ & 19 & 0.287 & 21 & $<0.001$ \\
\hline
\end{tabular}

produced that could be freely adopted by hospitals. Using the Delphi method, consensus was gained through three rounds. The content of the leaflet included information identified as lacking in previous studies such as when to start activities, and the relationship between exercises and driving. ${ }^{6}{ }^{19}$ Positive focus group comments supported that the leaflet was comprehensive to prevent patients feeling disempowered and abandoned. ${ }^{6}$

Prior to surgery, patients identify their own boundaries according to pain and movement during activities such as housework. Postsurgery, these boundaries do not exist and this can contribute to fear-avoidance behaviour, along with other factors including: patients not understanding spinal anatomy; being afraid that moving will undo the surgery; and being unsure of how far to move safely. ${ }^{6}$ The patient focus group found that patients wanted specific examples of everyday tasks and highimpact and low-impact activities with simple instructions to enable them to regain activity and function, to prevent fear-avoidance behaviour. They also requested that the leaflet clarified whether activity and exercise presented any issues with, for example, stitches so that they were fully informed. The leaflet provides new boundaries through the provision of milestones and the opportunity for the physiotherapist to provide individually tailored exercises. Providing milestones and timescales, although not advocated by all clinicians, might go some way to preventing fear-avoidance behaviour. ${ }^{6}$

It was not clear prior to the study, whether exercises would be recommended for inclusion in the leaflet by the panel of stakeholders, especially because of the lack of evidence for the effectiveness of physiotherapy intervention postsurgery. ${ }^{10}$ In fact, consensus was reached early about their inclusion, including specific types of exercises. It was clear early on that clinicians wanted options regarding intensity and duration of exercises to enable them to make the leaflet patient specific. The need for the inclusion of exercises in patient information for discectomy patients has been highlighted in other work. ${ }^{20}$ In a study to determine the patients views about the booklet 'Your Back Operation' following its use in an $\mathrm{RCT}^{20}$ patients wanted advice on exercises, including type, duration, frequency and intensity, and other information on pain control, driving, wound care and infection management/prevention. Our leaflet provides this information.
By using the Delphi method and focus groups, and including patients as panel members, the leaflet has addressed the needs of the end users, preventing the feelings of disempowerment and abandonment. ${ }^{6} 20$ The key benefit of using the Delphi technique is that it seeks to obtain consensus recommendations from experts through structured anonymised questionnaires. Although open questions were included in all rounds, there was a reduction in free text comments as rounds progressed, reinforcing the quantitative observations of convergence. ${ }^{21}$ For example, in round 2, 25\% of questions under the heading 'Normal anatomy of the spine' reached consensus, yet in round 3,100\% agreement was achieved. The focus groups allowed patients and clinicians to discuss the draft leaflet intervention from their separate perspectives. Issues regarding the understanding of illustrations and exercises arose. The quality of the discussion and agreement was good, facilitated by the focus group being specifically for patients, as homogeneity of panel members is important. ${ }^{18}$ If panel members have not had similar experiences, then there is a risk of false consensus.

Limitations of the study include a low response rate for the Delphi method and although this is a well-recognised limitation, ${ }^{16}$ the optimum number is unclear. ${ }^{22}$ Where the panel members are homogeneous, 10-15 members could be sufficient. The study started with 11 patients and 17 surgeons; this fell to 2 patients and 1 surgeon in round 2, and finally 3 patients and 2 surgeons in round 3. Physiotherapy input was consistently higher. Feedback from panel members was that the questionnaire was too long and their workload prevented them from taking part. Non-responders can significantly affect the interpretation of percentages and this could lead to misleading oscillatory movements. ${ }^{23}$ Although the unbalanced return rate in the Delphi could lead to a possibility of bias towards physiotherapists' views, the patient focus groups will have gone some way towards rebalancing this.

Because there is a lack of evidence for the effectiveness of physiotherapy intervention postsurgery, ${ }^{10}$ developing a lumbar discectomy leaflet for patients based on the consensus of stakeholders including surgeons, physiotherapists and patients is all the more important. The combined approach of the Delphi method and focus groups produced a leaflet where each participant agrees with both the issues under consideration and with each other. The leaflet is comprehensive, yet simple, and 
Table 5 Sections and subsections of final leaflet

\author{
Sections \\ The purpose of this manual \\ What is the spine? \\ What is a disc? \\ What has happened to my disc? \\ What is the aim of lumbar discectomy surgery? \\ What happens during surgery? \\ The benefit of lumbar discectomy surgery \\ What are the risks? \\ How should I feel after the surgery? \\ Going home \\ Being active \\ Timescales to guide you
}

What exercises should I do and how should I do them?

Day to day advice-prevention is better than cure

Pace yourself

Frequently asked questions

\section{Subsections}

References

Will my symptoms go after surgery

How soon can I get up after my surgery?

Will I be in pain?

Will I receive physiotherapy following surgery?

How long will I stay in hospital?

When do my stitches come out?

How long will it take to recover?

When will I be able to walk?

How soon can I have a bath after surgery?

When will I be able to walk up the stairs?

When can I return to work?

When can I drive?

When can I have sex?

When should I return to low-impact exercise and sport?

When should I return to high-impact exercise and sport?

When can I lift?

Useful contacts

contains illustrations of exercises that can be tailored to the individual. Future work will include evaluating this leaflet's effectiveness as part of an RCT.

\section{Author affiliations}

${ }^{1}$ Department of Health Professions, Manchester Metropolitan University, Manchester, UK

${ }^{2}$ School of Sport, Exercise and Rehabilitation Sciences, College of Life and Environmental Sciences, University of Birmingham, Birmingham, UK

${ }^{3}$ Physiotherapy Department, Royal Liverpool and Broadgreen University Hospitals NHS Trust, Liverpool, UK

${ }^{4}$ Physiotherapy Department, Newcastle upon Tyne Hospitals NHS Foundation Trust, Newcastle, UK

${ }^{5}$ Physiotherapy Department, The Robert Jones and Agnes Hunt Orthopaedic and District Hospital NHS Trust, Oswestry, UK
${ }^{6}$ Physiotherapy Department, University Hospitals Birmingham NHS Foundation Trust, Birmingham, UK

${ }^{7}$ Physiotherapy Department, Salford Royal NHS Foundation Trust, Salford, UK

Acknowledgements The authors would like to thank the patients, including Claire Littleford and Christopher Bayliss, and all physiotherapists and surgeons that took part in this study.

Contributors PCG and AR were involved in the conception, analysis and drafting of the work. CCW made substantial contribution to the interpretation of data and critical revision. LW, EP and $\mathrm{AH}$ contributed to the design, acquisition of data and revision of the work. LC and CA contributed to the concept, acquisition of data and intellectual content. All authors reviewed the work at various stages, gave approval of final version and agree to be accountable for all aspects of the work. PCG is the guarantor. 
Funding This work was supported by The Queen Elizabeth Hospital Birmingham Charity.

Competing interests None.

Patient consent Obtained.

Ethics approval This study obtained approval from the Manchester Metropolitan University.

Provenance and peer review Not commissioned; externally peer reviewed.

Data sharing statement No additional data are available.

Open Access This is an Open Access article distributed in accordance with the Creative Commons Attribution Non Commercial (CC BY-NC 4.0) license, which permits others to distribute, remix, adapt, build upon this work noncommercially, and license their derivative works on different terms, provided the original work is properly cited and the use is non-commercial. See: http:// creativecommons.org/licenses/by-nc/4.0/

\section{REFERENCES}

1. HESonline. Main procedures and interventions: 3 characters [V33] http://www.hscic.gov.uk/hes (accessed 9 May 2014).

2. Bradshaw $\mathrm{C}$, Pritchett $\mathrm{C}$, Bryce $\mathrm{C}$, et al. Information needs of general day surgery patients. Ambul Surg 1999;7:39-44.

3. Magnusson ML, Pope MH, Wilder DG, et al. Is there a rational basis for post-surgical lifting restrictions? 1. Current understanding. Eur Spine J 1999;8:170-8.

4. McGregor AH, Dicken B, Jamrozik K. National audit of postoperative management in spinal surgery. BMC Musculoskelet Disord 2006;7:47.

5. Williamson E, White L, Rushton A. A survey of postoperative management for patients following first time lumbar discectomy. Eur Spine J 2007;16:795-802.

6. Williamson J, Bulley C, Coutts F. What do patients feel they can do following lumbar microdiscectomy? A qualitative study. Disabil Rehabil 2008;30:1367-73.

7. Royal College of Surgeons. Get well soon-discectomy. http://www. rcseng.ac.uk/patients/recovering-from-surgery/discectomy/ (accessed 9 May 2014).

8. Waddell G, Sell P, McGregor A, et al. Your back operation. London: The Stationary Office, 2005.

9. McGregor AH, Doré CJ, Morris TP et al. ISSLS prize winner: Function After Spinal Treatment, Exercise and Rehabilitation (FASTER): a factorial randomised trial to determine whether the functional outcome of spinal surgery can be improved. Spine (Phila Pa 1976) 2011;36:1711-20.

10. Rushton A, Wright C, Goodwin P, et al. Physiotherapy rehabilitation post first lumbar discectomy: a systematic review and meta-analysis of randomised controlled trials. Spine 2011:36:E961-72.

11. Selkowitz DM, Kulig K, Poppert EM, et al; Physical Therapy Clinical Research Network. The immediate and long-term effects of exercise and patient education on physical, functional, and quality-of-life outcome measures after single-level lumbar microdiscectomy: a randomized controlled trial protocol. BMC Musculoskelet Disord 2006;7:70

12. The Information Standard. 2009. http://www.theinformationstandard. org/ (accessed 9 May 2014)

13. McCarthy CJ, Rushton A, Billis V, et al. Development of a clinica examination in non-specific low back pain: a Delphi technique. J Rehabil Med 2006;38:263-7.

14. Ferguson FC, Brownlee M, Webster V. A Delphi study investigating consensus among expert physiotherapists in relation to the management of low back pain. Musculoskeletal Care 2008;6:197-210.

15. Duffield C. The Delphi technique: a comparison of results obtained using two expert panels. Int J Nurs Stud 1993;30:227-37.

16. Keeney S, Hasson F, McKenna H. Consulting the oracle: ten lessons from using the Delphi technique in nursing research. J Adv Nurs 2006;53:205-12.

17. Cross V. The same but different A Delphi study of clinicians' and academics' perceptions of physiotherapy undergraduates. Physiotherapy 1999;85:28-39.

18. Sim J, Snell J. Focus groups in physiotherapy evaluation and research. Physiotherapy 1996;82:189-98.

19. McGregor A, Burton A, Sell P, et al. The development of an evidence-based patient booklet for patients undergoing lumbar discectomy and un-instrumented decompression. Eur Spine $J$ 2007;16:339-46.

20. McGregor AH, Henley A, Morris TP, et al. Patients' views on an education booklet following spinal surgery. Eur Spine $J$ 2012;21:1609-15.

21. Holey EA, Feeley JL, Dixon J, et al. An exploration of the use of simple statistics to measure consensus and stability in Delph studies. BMC Med Res Methodol 2007;7:52

22. Hsu C-C, Sandford BA. The Delphi technique: making sense of consensus. Pract Assess Res Eval 2007;12:1-8. http://pareonline. net/getvn.asp? $v=12 \& n=10$

23. Scheibe M, Skutsch M, Schofer J. Experiments in Delphi methodology. In: Linstone HA, Turoff M. eds. The Delphi method: techniques and applications. Addison-Wesley, 1975:262-87. 